\title{
Study of the durability against carbonation of the concrete formulated with the partial replacement of cement with marble powder
}

\author{
Ahmed MERAH ${ }^{1}$ \\ ${ }^{1}$ University AmmarTelidji of Laghouat, Faculty of Civil Engineering and \\ Architecture, Research Laboratory of Civil Engineering (LRGC), Laghouat, Algeria. \\ E-mail:a.merrah@lagh-univ.dz
}

\begin{abstract}
The first aim of this study is the use of marble waste powder as a partial replacement with cement (CEMI 42.5) in concrete in order to reduce greenhouse gas emissions results in the cement production and consequently on the manufacturing concrete with less environmental impact.

Moreover, the carbonation phenomenon influences significantly the durability of reinforced concrete structures, in this context, the second aim of this work is the study of the effect of the accelerated carbonation on the durability of concretes formulated with the cement containing the marble waste (MDP) with different percentages. For this purpose, four concrete mixtures containing 0\%, 10\%, 15\%, and 30\% MDP as cement replacement by weight basis have been prepared. These mixtures of concretes were submitted to accelerated carbonation to study their durability against this phenomenon.

The series of tests are conducted to study the effect of 10\%, 20\% and 30\% replacement of cement with marble powder on carbonation depth and compressive strength and compare it with the conventional concrete.

The result of this present investigation indicates that the carbonation depth increases with the increase of the rate of the replacement of cement with waste marble powder (10 $\%$ to 30\%) and the compressive strength decreases slightly with the increase of replacement. the compressive strength remains within the acceptable range of M25 concrete.
\end{abstract}

Key words: waste marble powder, concrete durability, carbonation depth, compressive strength, environment.

\section{Introduction}

The consumption of fossil fuels releases trace gases in the atmosphere that affect the climate, such as methane, Sulphur dioxide, nitrogen and carbon dioxide. The latter being responsible for half of the greenhouse effect (Retallack and Conde 2020)[1]. (Betts et al 2016)[2] shown that the global carbon dioxide $\left(\mathrm{CO}_{2}\right)$ content of the atmosphere reaches the symbolic and significant threshold of 400 parts per million (ppm) for the first time in 2015 and set new records in 2016.

Concrete is the most widely used composite material in the world, given its high strength and stability. this material is mainly composed of cement, aggregates, water and possibly additives, all the components of this material are available in nature with the exception of the cement which requires fossil energy for production which is the main source of pollution air. 


\section{Ahmed Merah}

(Diet and Schmitt 1996)[3] show that the cement industry generates enormous quantities of carbon dioxide and thus participates in increasing the concentration of $\mathrm{CO}_{2}$ in the air. this concentration can reach $1 \%$ and to produce a ton of cement, the cement industry releases a ton of $\mathrm{CO}_{2}$.

Furthermore, marble quarries generate marble powder waste that is harmful to the environment. In this context, two objectives are to be expected, the first consists in limiting the $\mathrm{CO}_{2}$ on emissions due to the manufacture of cement, the second consists in minimizing the effects on the environment by the use of marble powder as a partial replacement for the cement, in this axe of research several researchers have carried out several studies on the effect of this partial replacement of cement with marble powder, among these researchers, (Sadek et al 2016)[4] conducted a study on the possibility of using marble powder in self-placing concrete as a partial replacement for cement, the results of this study showed that the optimal percentage of replacement is around $50 \%$ which leads to an increase in compressive strength . (Soliman 2013[5]; Aliabdo et al 2014[6]) studies the effect of the use of marble powder as a partial replacement of cement on the concrete properties, the results obtained shown that the use of marble powder improves workability, compressive and tensile strength. (Kumar and Kumar 2015[7], Vaidevi 2013[8]; Rodrigues et al 2015[9]; Ergün 2011[10]) studied the effect of different percentage of substitution of cement by marble powder on compressive strength, the results of this research shown that the optimal rate of replacement of cement by powder marble is up to $10 \%$. In the same way, (Singh et al 2017;2019) [1112 ]concluded that an optimum of $15 \%$ replacement leads to an improvement in strength and durability of concrete.

In the same way other researchers continued to explore this field, ( Singh et al 2019)[13], concluded that the marble powder incorporated in concrete shows increase in mechanical proper-ties at $15 \%$ replacement by weight of cement for lower $\mathrm{w} / \mathrm{b}$ ratios 0.35 and 0.40 , and for $w / b$ ratio 0.45 the strength increases only up to $10 \%$ replacement. In their study, (Ulubeyli et al 2016[14]) found out that the use of waste marble in the conventional or self-compacting concrete can improve durability properties of the concrete.

In their study (Vardhan et al 2019) [15] show that waste marble can be used into concrete to improve its strength and permeation properties, with the maximum improvement obtained at 40\% replacement level. (Ashish 2018) [16] concluded in their study that the maximum percentage of partial replacement of marble powder in cement don't exceed $20 \%$.

The studies cited in this work in the field of partial replacement of cement with marble dust conclude that the replacement of the cement must not exceed $20 \%$ of marble dust in order to have acceptable compressive strength of the concrete. High levels of marble dust increase the capillarity of concrete.

On the other hand, many environmental phenomena influence the durability of reinforced concrete structures. Among these phenomena, we can cite the concrete carbonation which is one of the main factors of degradation of unprotected reinforced concrete structures, and those exposed to high concentrations of carbon dioxide (such as road tunnels). This causes corrosion of the reinforcements, causing the concrete to 
Study of the durability against carbonation of the concrete formulated with the partial replacement of cement with marble powder

lose its alkalinity and consequently causes the reduction of the service life of reinforced concrete structures. carbon dioxide gas penetrates through the open porosity of concrete to react with interstitial water to give carbonic acid, this in turn reacts with portlandite $\mathrm{Ca}(\mathrm{OH})_{2}$ (product responsible for the durability of the steels against corrosion while keeping an environment with a basic $\mathrm{pH}$ of the order of 13), this reaction produces calcium carbonate $\mathrm{CaCO}_{3}$ which consumes the reserve of portlandite and putting steels without protection. Then, lead to disorders in the construction by swelling and cracking.

Several researchers have studied the effect of carbonation, on the durability of concretes formulated with substitution of cements with marble powder, in their study (Ashish 2019[17]; Gameiro 2014[18]) shows that the depth of carbonation increases with the increase of the replacement.

(Singh et al 2017[19]) shows that with $15 \%$ of partial replacement of the marble powder, the re-sistance for carbonation was improved. According to the experimental study, (Ashish 2018[20]; Rana et al 2015[21]) also show that the depth of carbonations increased in case of use of powder marble.

In their review study, (Kumar and Thakur 2018[22]) show that the concrete carbonation depth depends on its porosity. Carbonation values also decrease with inclusion of marble powder and reported a similar trend to carbonation depth and water absorption by immersion for the chloride mitigation coefficient.

This paper presents a contribution in this area. this contribution consists on studying the durability of concrete formulated with a partial replacement of cement with marble powder who is the first objective, the second consist to study the effect of using marble powder as partially replace of cement on the durability of concrete against the phenomenon of concrete carbonation.

The result of this investigation indicates that the carbonation depth decreases with the increase of the replacement of cement with waste marble powder (10\% to 30\%) and the compressive strength decreases slightly with the increase of replacement. the compressive strength remains within the acceptable range of M25 concrete.

\subsection{Powder Marble}

The used marble powder was a waste resulting from the cutting, shaping and lustration of marble stones. This powder was supplied by the company MCA (Marble Tile and Agglo-marble installed in locality of Bordj Bou Arrérdj in Algeria). The physic and the chemical properties of the marble powder are given in Table 4.

Table 4:

Chemical properties of the marble powder [23]

\begin{tabular}{|c|c|}
\hline Content (\%) & Marble powder \\
\hline $\mathrm{CaO}$ & 55.6 \\
\hline $\mathrm{SiO}_{2}$ & 0.6 \\
\hline $\mathrm{AL}_{2} \mathrm{O}_{3}$ & 0.4 \\
\hline
\end{tabular}


Ahmed Merah

\begin{tabular}{|c|c|}
\hline $\mathrm{Fe}_{2} \mathrm{O}_{3}$ & 0.2 \\
\hline $\mathrm{MgO}$ & 0.1 \\
\hline $\mathrm{NaCO}_{3}$ & 90 \\
\hline $\mathrm{CL}$ & 0.1 \\
\hline LOI & 43 \\
\hline Density & 2.7 \\
\hline $\begin{array}{l}\text { Blaine Specific } \\
\text { Surface }\left(\mathrm{cm}^{2} / \mathrm{g}\right)\end{array}$ & 2126 \\
\hline
\end{tabular}

The used sand is alluvial $(0-5 \mathrm{~mm})$ which produced by Oued M'zi quarry of Laghouat, Algeria , two classes of limestone aggregates (3-8 $\mathrm{mm}$ and $8-15 \mathrm{~mm}$ ) were used in the concrete formulation which produced by the quarry (Laghouat).

The table 5 gives the physical proprieties of the used aggregates

Table 5:

Physical proprieties of the used aggregates

\begin{tabular}{|l|l|l|l|l|}
\hline Physical proprieties of the used & \multirow{2}{*}{ Standard } & \multicolumn{2}{|l|}{ Aggregates } \\
\cline { 4 - 5 } aggregates & & Sand & Gravel \\
\cline { 3 - 5 } & & $0 / 5$ & $3 / 8$ & $8 / 15$ \\
\hline Apparent Density $\left(\mathrm{g} / \mathrm{cm}^{3}\right)$ & & 1.564 & 1.319 & 1.255 \\
\hline Absolute density $\left(\mathrm{g} / \mathrm{cm}^{3}\right)$ & 2.6 & 2.65 & 2.65 \\
\hline Absorption Coefficient $(\%)$ & NF P 18-554 & 1 & 1.5 & 1.5 \\
\hline
\end{tabular}

The used sand has a particle size of $0-5 \mathrm{~mm}$, apparent density of $1.56 \mathrm{~g} / \mathrm{cm}^{3}$ and absolute density of $2.61 \mathrm{~g} / \mathrm{cm}^{3}$. Two sizes of aggregates $(3-8 \mathrm{~mm}),(8-15 \mathrm{~mm})$ are used to formulate the concretes, these aggregates are characterized by a calcareous rock with a high calcium carbonate content ( $\left(98 \% \mathrm{CaCO}_{3}\right)$, their apparent densities are $1.32 \mathrm{~g} / \mathrm{cm}^{3}$ and $1.26 \mathrm{~g} / \mathrm{cm}^{3}$ respectively. Their absolute density is $2.6 \mathrm{~g} / \mathrm{cm}^{3}$. The used water is tap water. It meets all the requirements of NFP 18-303 and EN 1008, taking into account the concentrations of suspended solids and dissolved salts.

\section{Methods}

\subsection{Concretes Formulations}

The used concrete formulation method in the present study is DREUX GORISSE method.

The results of the concrete formulation were gives in Table 6: 
Study of the durability against carbonation of the concrete formulated with the partial replacement of cement with marble powder

Results of control concrete Formulation

Table 6:

\begin{tabular}{|c|c|c|c|c|c|c|c|}
\hline $\mathrm{S} / \mathrm{G}$ & $\mathrm{W} / \mathrm{C}$ & $\begin{array}{l}\text { Sand } \\
\left(\mathrm{kg} / \mathrm{m}^{3}\right)\end{array}$ & $\begin{array}{l}\text { Gravel } \\
3 / 8(\mathrm{~kg})\end{array}$ & $\begin{array}{l}\text { Gravel } \\
8 / 15(\mathrm{~kg})\end{array}$ & $\begin{array}{l}\text { Cement } \\
\text { (CEM I) } \\
(\mathrm{kg})\end{array}$ & $\begin{array}{l}\text { Water } \\
\text { (L) }\end{array}$ & $\begin{array}{l}\text { Slump test } \\
(\mathrm{cm})\end{array}$ \\
\hline 0.60 & 0.57 & 683.7 & 146.7 & 990.25 & 374.4 & 216.42 & 8 \\
\hline
\end{tabular}

Legend:

S: Sand

G: Gravels

W: Water

C: Cement

Table 6: shows the results of the control concrete formulation. According to the synthesis of this results, the concrete formulation has the density, who is a normal concrete according the standard NF EN 12350-6 (Normal concrete with a density between 2000 and $2600 \mathrm{~kg} / \mathrm{m}^{3}$ ).

From this control concrete formulation, three other concrete mixes were formulated by substituting different percentages $(10 \%, 20 \%$ and $30 \%)$ of cement replace by weight with marble powder according to Table 7

Table 7:

Weights of Marble powder for different concrete formulations.

\begin{tabular}{|l|l|l|}
\hline Concretes formulations & Cement $(\mathrm{Kg})$ & Marble powder $(\mathrm{Kg})$ \\
\hline B1 $(0 \%$ replacement $)$ & 374.4 & 0 \\
\hline B2 (10\% replacement) & 336.96 & 37.44 \\
\hline B3 (20\% replacement) & 299.52 & 74.88 \\
\hline B4 (30\% replacement) & 262.08 & 112.32 \\
\hline
\end{tabular}

\subsection{Confection and preservation of samples.}

Before mixing the concretes, the aggregates, previously washed and dried in an oven at $10 \pm 5^{\circ} \mathrm{C}$ for one day $(24 \mathrm{~h})$, then cooled in ambient air, then they are introduced, according to mass proportions already known. in parallel with the preparation of the concrete, the moulds $(7 \times 7 \times 7 \mathrm{~cm} 3)$ are prepared for the determination of the compressive strength and for the accelerated carbonation tests. All the samples are kept in the moulds for 24 hours in plastic film, after demoulding, they are immersed in 
water at $\mathrm{T}=20 \pm 0.5^{\circ} \mathrm{C}$ according to standard NA 426 for 28 days and according to the recommendation of the AFPC AFREM[23](P.Rougeau,1997), until the deadlines for the start of tests (Figure 1)

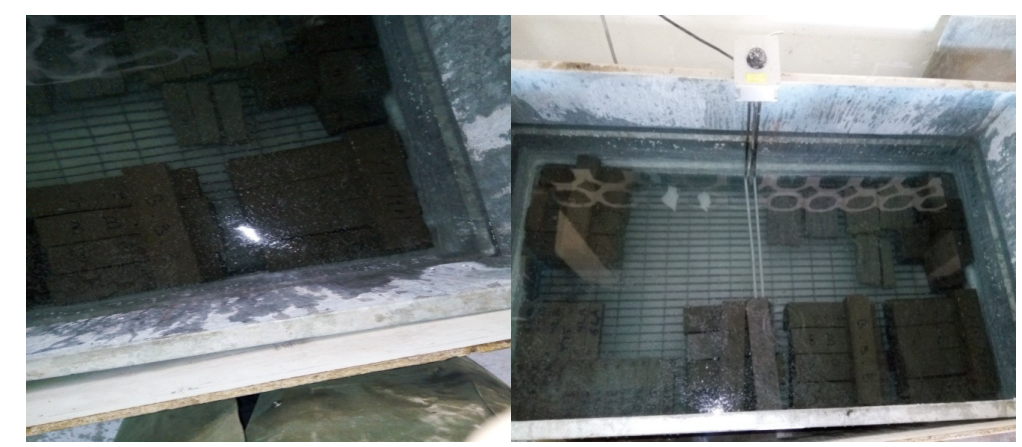

Fig. 1. Samples conservation.

After 28 days of cure, the cubic samples $\left(7 \times 7 \times 7 \mathrm{~cm}^{3}\right)$ of prepared concrete will be subjected to two test campaigns, compression test and accelerated carbonation test.

\subsection{Compressive strength test.}

In order to determinate the compressive strength of the four concrete formulations (B1, B2, B3 and B4) cubic samples $\left(7 \times 7 \times 7 \mathrm{~cm}^{3}\right)$ were used. The compressive strength for cubic samples of carbonated and control concrete samples were determinate at age 7,14 and 28 days.

The compression resistance test was carried out on $7 \times 7 \times 7 \mathrm{~cm}^{3}$ cubic samples according to NF P18-406. The hydraulic press used has a loading speed of $0.5 \mathrm{MPa} /$ Sec with a capacity of $3000 \mathrm{KN}$. the rupture stress is given directly by the testing machine with an accuracy of 0.5 $\mathrm{MPa}$ (Figure 2.).

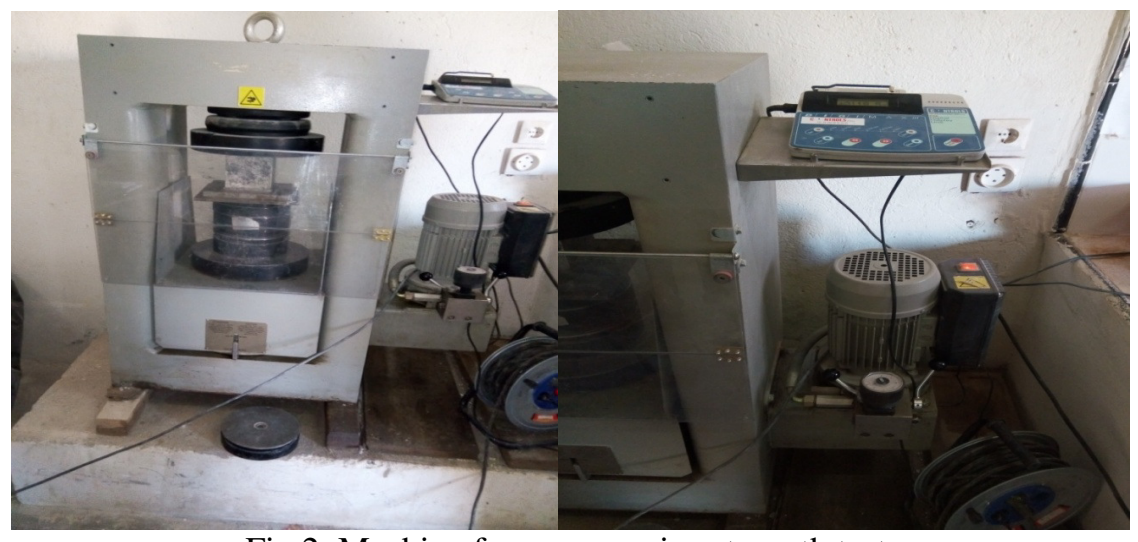

Fig.2. Machine for compressive strength test.

\subsection{Accelerated carbonation test}

The concrete carbonation is a very slow phenomenon in the atmosphere, the concentration of carbon dioxide is not very important (of the order of $0.3 \%$ ) in the air, the effect of this phenomenon is manifested only after several years of exposure of 
Study of the durability against carbonation of the concrete formulated with the partial replacement of cement with marble powder

reinforced concrete structures to this phenomenon, therefore, it is necessary to find a way to accelerate the carbonation of the cementitious material ensuring results representative of this natural phenomenon. This test is called "accelerated carbonation test".

\subsubsection{Accelerated carbonation test procedure according to the AFPC-AFREM test protocol.}

The test consists in following the evolution of the thickness of the carbonated concrete preserved in an atmosphere rich in carbon dioxide $\left(\mathrm{CO}_{2}\right)$.

\section{A.1. Equipment.}

$\checkmark \quad$ Ventilated oven: controlled at $40 \pm 2{ }^{\circ} \mathrm{C}$, located in a room with a temperature of $20 \pm 2{ }^{\circ} \mathrm{C}$

$\checkmark \quad$ Accelerated carbonation chamber: the accelerated carbonation test consists in obtaining a gas mixture $\left(50 \% \mathrm{CO}_{2}+50 \%\right.$ air) in the carbonation chamber (Figure. 3$)$ with controlling the relative humidity which must be between 40 and $80 \%$. To monitor the relative humidity, a hygrometer was used. The carbonation test is executed using a carbon dioxide $\left(\mathrm{CO}_{2}\right)$ incubator according to the AFPC-AFREM test protocol [23](1997) (P. Rougeau,1997).

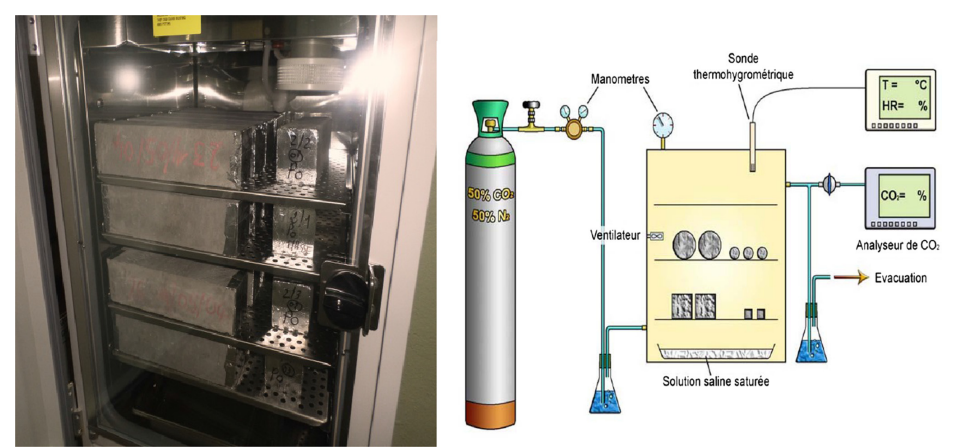

Fig.3. Accelerated carbonation chamber

To start the accelerated carbonation test, the samples must be preconditioned in two phases:

- In the first phase, the specimens undergo a cure in a humid environment (relative humidity greater than $95 \%$ or emerged into water) for 28 days (P. Rougeau, 1997) then weighed, according to the recommended procedure for determining the bulk density and the water content.

In the second phase, they are placed in an oven at $40 \pm 2^{\circ} \mathrm{C}$, for two days, then weighed for second time [23] (P. Rougeau,1997). The two faces of each sample must be covered with adhesive aluminium wrapper to guide the diffusion of $\mathrm{CO} 2$, then the samples are subjected to accelerated carbonation in the carbonation chamber for 28 days and placed distant of $2 \mathrm{~cm}$ one from the other (figure 4 and figure 5) [23] (P.Rougeau, 1997), while other control samples are stored in the laboratory to measure the compressive strength. 


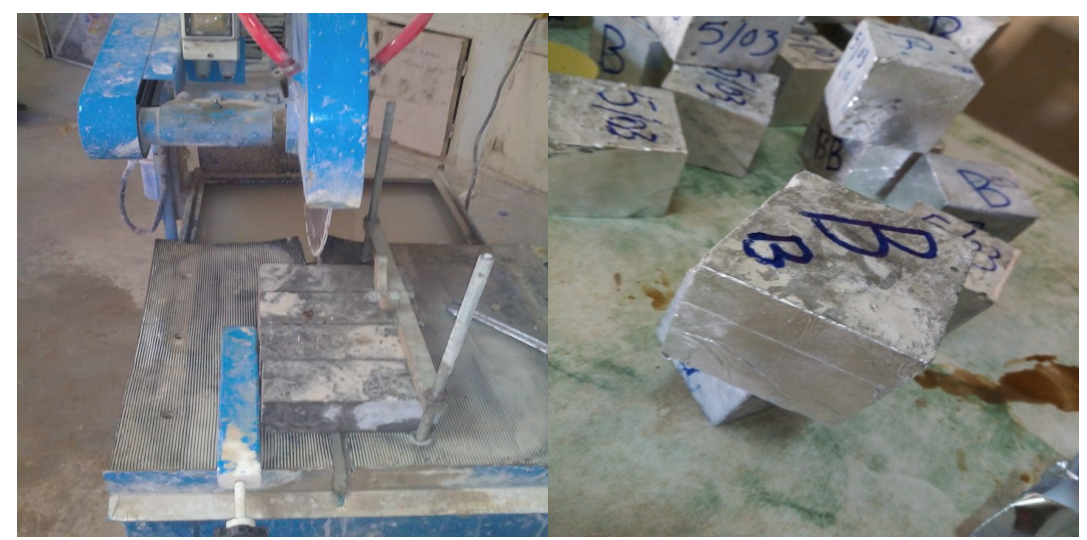

Fig. 4.: Preparation of Samples for accelerated carbonation test.

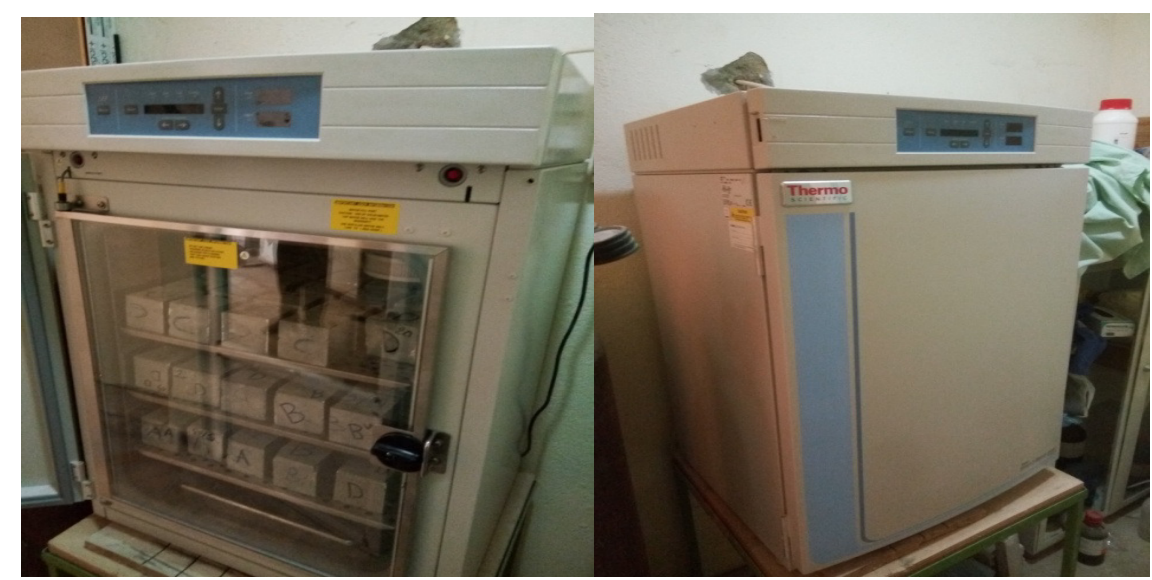

Fig.5. Samples into the chamber of carbonation

At the age 7, 14 and 28 days, concrete samples are weighed and removed from the carbonation chamber to measure the evolution of accelerated carbonation according to the experimental procedures of the AFPC AFREM 1997 recommendations (P. Rougeau, 1997). To measure the concrete carbonated depth, the samples are sliced in two parts and the reading is made immediately using the colour indicator recommended by the procedure of standard NF P18-458. It colours the uncarbonated concrete in pink while the carbonated concrete does not change. The colour indicator used to reveal the carbonated concrete is a phenolphthalein solution (Figure. 6). The number of samples required for carbonation test is four: three for measuring the concrete carbonation depth, the fourth is used to follow the evolution of the sample mass during the test. Two additional test specimens may be used to monitor the evolution of concrete subjected to natural carbonation. These samples can be stored in an ambient atmosphere at a temperature of $20 \pm 2 \_\mathrm{C}$ and a relative humidity of $65 \pm$ $5 \%$. Other cubic samples were prepared for the different concrete formulations according to the recommendations of the French Association of Competitiveness Clusters (AFPC AFREM 1997) [23] (P. Rougeau,1997). 
Study of the durability against carbonation of the concrete formulated with the partial replacement of cement with marble powder

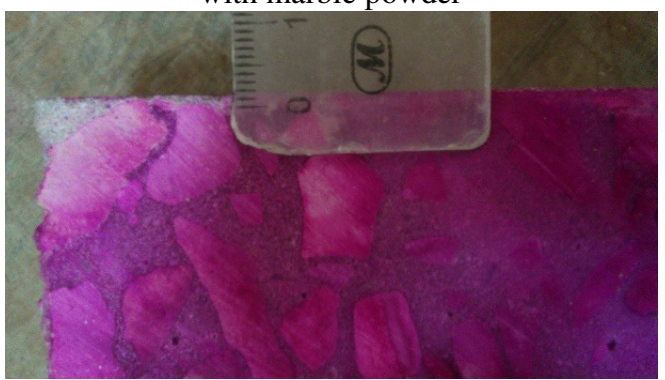

Fig.6. Determination of Carbonation depth with phenolphthalein pulverisation

\section{Results and Discussions}

\subsection{Densities and water content of samples}

In order to conduct the accelerated carbonation test and according to AFPC AFREM 97 [23](P. Rougeau,1997) recommendations, in the first pre-conditioning phase, the bulk density and water content of the samples must be determined for the accelerated carbonation test.

The table 8 show the results of densities and water content for the four-concrete formulation

Densities and water content for the four concrete formulations

Table 8:

\begin{tabular}{|l|l|l|}
\hline Concrete formulations & Densities in $\mathrm{Kg} / \mathrm{m}^{3}$ & Water content $(\%)$ \\
\hline B1 $(0 \%$ replacement $)$ & 2537.63 & 2.37 \\
\hline B2(10\% replacement $)$ & 2566.14 & 2.32 \\
\hline B3(10\% replacement $)$ & 2602.85 & 2.32 \\
\hline B4(10\% replacement $)$ & 2592.64 & 2.34 \\
\hline
\end{tabular}

The table 8 show that the densities increases with the increase of substitution (cement with the powder marble) for the four concrete formulations. The water content of the all concrete formulations have the same value, from these results, then, the accelerated carbonation test can be started according to AFPC AFREM 97[23] (P. Rougeau,1997).

\subsection{Effect of the replacement (cement by the powder marble) on the compressive strength for the four concretes formulations}

At the age of 28 days, samples were tested with the compressive machine, the table 9 show the effect of the carbonation on the compressive strength of the control concrete and the other concretes with different percentages of replacements of cement with powder marble $(10 \%, 20 \%$ et $30 \%)$ 
Ahmed Merah

Table 9:

Compressive strength for different concrete formulations

\begin{tabular}{|c|c|c|c|c|}
\hline \multirow{2}{*}{$\begin{array}{l}\text { Age } \\
\text { (days) }\end{array}$} & \multicolumn{4}{|c|}{ Compressive strength (MPa) } \\
\hline & $\begin{array}{l}\text { Formulation } \\
\text { B1(control) }\end{array}$ & $\begin{array}{l}\text { Formulation B2 } \\
\text { (10\%replacement) }\end{array}$ & $\begin{array}{l}\text { Formulation B3 } \\
\text { (20\% replacement) }\end{array}$ & $\begin{array}{l}\text { Formulation } \mathrm{B} 4 \\
\text { (30\% replacement) }\end{array}$ \\
\hline 28 & 59.2 & 55.4 & 52.9 & 46.4 \\
\hline
\end{tabular}

from Table 9 and the figure 7, it is clearly shown that the compressive strength decreases with increasing percentage of substitution of cement with marble powder. this decrease is slightly (of the order of 11\%) up to a percentage of $20 \%$ of substitution and it is important of the order of $22 \%$ for a substitution of $30 \%$.

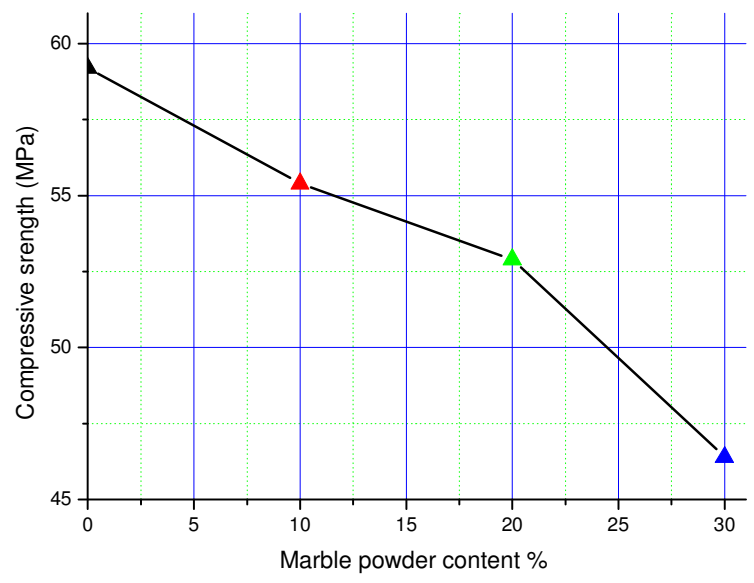

Fig.7.: Compressive strength with marble powder content

The obtained results for the compressive strength of concrete are in agreement with those obtained by [24](Tayeh 2018). The value of the compressive strength of $46 \mathrm{MPa}$ corresponding to a substitution of cement with $30 \%$ of marble powder is acceptable for the realization of structural elements of reinforced concrete. this result will lower cost of making reinforced concrete structures, with condition to protecting the exposed concrete against carbonation.

\subsection{Effect of the carbonation on the gain mass for the four concrete formulations}

The table 10 show the effect of the carbonation on the gain mass for the four concrete formulations at the different ages 7,14 and 28 days, 
Study of the durability against carbonation of the concrete formulated with the partial replacement of cement with marble powder

Table 10:

Mass gain $(\mathrm{g})$ for different concrete formulations.

\begin{tabular}{|l|l|l|l|l|}
\hline \multirow{2}{*}{ Age (days) } & \multicolumn{5}{|l|}{ Mass gain $(\mathrm{g})$} & $\begin{array}{l}\text { Concrete B1 } \\
\text { (control) }\end{array}$ & $\begin{array}{l}\text { Concrete B2 } \\
(10 \% \text { replacement })\end{array}$ & $\begin{array}{l}\text { Concrete } \\
(20 \% \\
\text { replacement })\end{array}$ & $\begin{array}{l}\text { Concrete } \\
(30 \% \\
\text { replacement })\end{array}$ \\
\hline 7 & 853.24 & 865.92 & 881.7 & 913.3 \\
\hline 14 & 856.8 & 869.2 & 886.8 & 923.1 \\
\hline 28 & 858.2 & 870.6 & 889.1 & 925.6 \\
\hline
\end{tabular}

From this table, we draw the following curve (Figure 8)

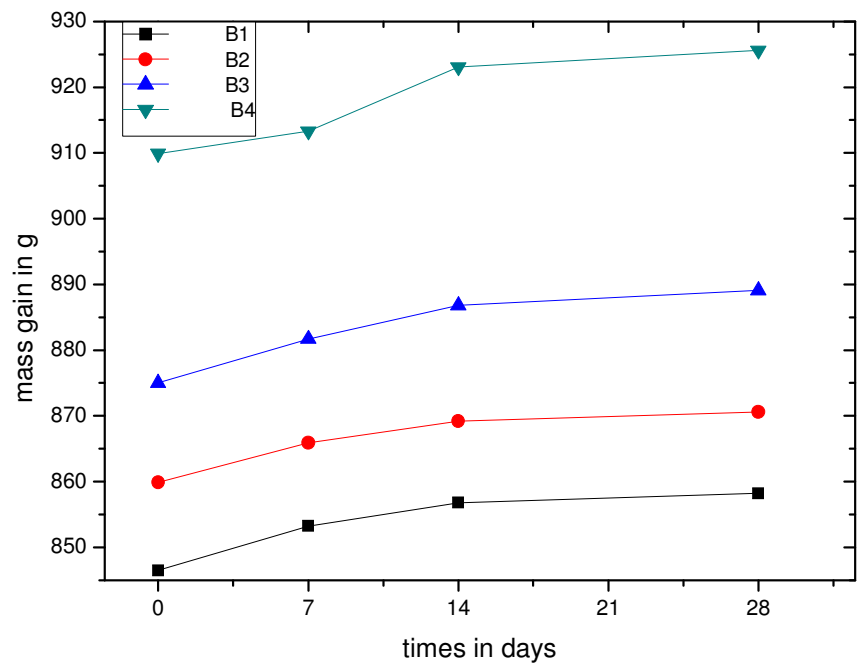

Fig.8.: Mass gain for the four concretes formulations

Figure. 8 show that the carbonation increases the mass of samples with the increase of the substitution (cement by marble powder $(10 \%, 20 \%, 30 \%)$. This increase is due mainly to the concrete carbonation who makes changes in the microstructure of carbonated concrete (replacement of portlandite by calcite).

\subsection{Effect of the accelerated carbonation on the four concretes formulations.}

The carbonate depth was determined, according to the AFPC-AFREM 97 procedure [23] (P.Rougeau,1997), by a phenolphthalein method described above, applied to the face of the cubic samples $\left(7 \times 7 \times 7 \mathrm{~cm}^{3}\right)$ after cutting into two parts with the 'ages 7 , 14 and 28 days. Table 11: shows the evolution of the depth of carbonation at different ages for the four concrete formulations. 
Evolution of carbonation depth at different ages for the four concrete formulations

\begin{tabular}{|l|l|l|l|l|}
\hline \multirow{2}{*}{ Age (Days) } & \multicolumn{4}{|l|}{ Carbonation depth (mm) } \\
\cline { 2 - 6 } & $\begin{array}{l}\text { Concrete } \\
\text { (Control) }\end{array}$ & $\begin{array}{l}\text { B2 } \\
\text { replacement) }\end{array}$ & $\begin{array}{l}\text { B3(20\% } \\
\text { replacement) }\end{array}$ & $\begin{array}{l}\text { B4(30\% } \\
\text { replacement) }\end{array}$ \\
\hline 7 & 1 & 3 & 4 & 6 \\
\hline 14 & 2 & 5 & 7 & 8 \\
\hline 28 & 3 & 6 & 7.5 & 9.5 \\
\hline
\end{tabular}

From the table 11, we draw the following curve (figure 9).

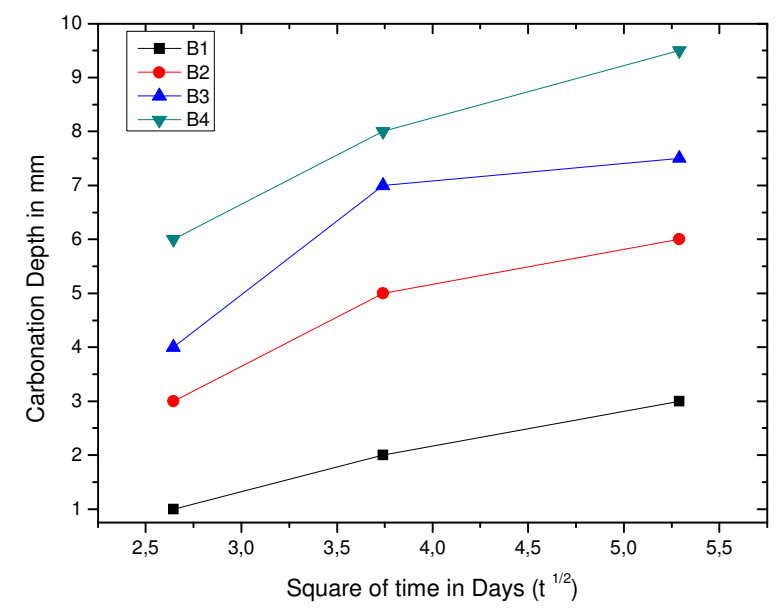

Fig.9.: Carbonation depth for the four concrete formulations

According to the curve of the evolution of the carbonation depth with the square of time for the different concretes, we note that the depth of the carbonation increases with the substitution of cement by the marble powder $(10 \%, 20 \%, 30 \%)$.

In addition, it can be seen from the previous curve (Figure 9) that the evolution of the carbonation depth is relatively fast from 7 days to 14 days and stabilizes at almost constant values until the 28th days. This for all concretes (B1, B2, B3, B4). This result can be explained as follows:

- $\quad$ During the 7 to 14-day period, the available amount of portlandite is larger, resulting in faster carbonation with calcite formation.

- $\quad$ For the period between 14 and 28 days, the available amount of portlandite becomes low as it is consumed during the first period. this will reduce the carbonation rate.

This reduction is caused by clogging of pores caused by the formation of calcite which has a molar volume greater than the molar volume of portlandite.

On the other hand, it can be concluded that the depth of carbonation increases with the increase of the percentage of replacement of powder marble. 
Study of the durability against carbonation of the concrete formulated with the partial replacement of cement with marble powder

\subsection{Correlation between the mass gain and the carbonation depth}

The figure 10 show the mass gain with carbonation depth

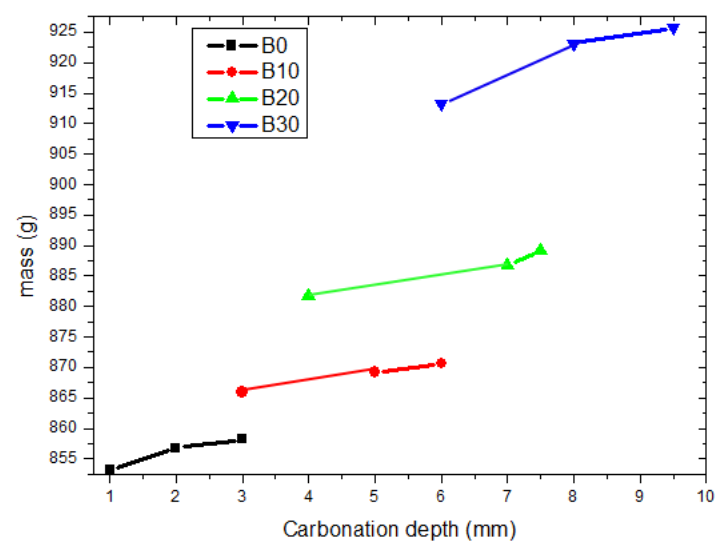

Fig 10. Mass gain with the carbonation depth

From the figure 10, it can be seen that the mass of the carbonated samples increases with the increase of the carbonation depth, which shows an important relation between the gain of the mass and the carbonation depth, which leaves to think that there is a relation which links the gain of mass to the depth of carbonation, that is to say that one can estimate the depth of carbonation from a simple weighing, thus avoiding the use of solution of phenol.

\section{Conclusions}

From this study, the following conclusions can be written

- The depth of carbonation increases with the time of exposure in the enclosure of accelerated carbonation.

The increase in the substitution of cement by powdered marble increases the depth of carbonation. this is due to the replacement of cement by the marble powder which makes decreased, the rate of portlandite and consequently, it accelerates the consumption of this one by the reaction of carbonation.

- $\quad$ The increase in the mass of carbonate samples increases with the increase in the depth of carbonation, this is mainly due to the carbonation of portlandite giving rise to calcite denser than portlandite

- The compressive strength decreases with substitution of the cement by the marble powder. this decrease is slight and remains within values acceptable by Algerian standards.

- $\quad$ Partial replacement of cement with marble powder up to $30 \%$ can give a quality concrete (Acceptable compressive strength according to Algerian standards). moreover, this replacement contributes to reducing the harmful effects of marble waste on the environment. 
Ahmed Merah

- $\quad$ To protect this concrete and make it durable against carbonation, it must be protected by an anti-carbonation coating.

\section{References}

[1] Retallack, G.J., Conde, G.D., 2020. Deep time perspective on rising atmospheric CO2. Global and Planetary Change 103177.

[2] Betts, R.A., Jones, C.D., Knight, J.R., Keeling, R.F., Kennedy, J.J., 2016. El Niño and a record CO 2 rise. Nature Climate Change 6, 806.

[3] Diet, A., Schmitt, A., 1996. Electricity of France and renewable energies: this is part Solar systems (Review) 17-23.

[4] Sadek, D.M., El-Attar, M.M., Ali, H.A., 2016. Reusing of marble and granite powders in selfcompacting concrete for sustainable development. Journal of Cleaner Production 121, 19-32.

[5] Soliman, N.M., 2013. Effect of using marble powder in concrete mixes on the behavior and strength of RC slabs. International Journal of Current Engineering and Technology 3, 1863-1870.

[6] Aliabdo, A.A., Elmoaty, A.E.M.A., Auda, E.M., 2014. Re-use of waste marble dust in the production of cement and concrete. Construction and building materials 50, 28-41.

[7] Kumar, R., Kumar, S.K., 2015. Partial replacement of cement with marble dust powder. International Journal of Engineering Research and Applications 5, 106-114.

[8]Vaidevi, C., 2013. Study on marble dust as partial replacement of cement in concrete. Indian journal of engineering 4, 14-16.

[9] Rodrigues, R., De Brito, J., Sardinha, M., 2015. Mechanical properties of structural concrete containing very fine aggregates from marble cutting sludge. Construction and Building Materials 77, 349-356.

[10] Ergün, A., 2011. Effects of the usage of diatomite and waste marble powder as partial replacement of cement on the mechanical properties of concrete. Construction and building materials $25,806-812$.

[11] Singh, M., Srivastava, A., Bhunia, D., 2017. An investigation on effect of partial replacement of cement by waste marble slurry. Construction and Building Materials 134, 471-488.

[12] Singh, M., Srivastava, A., Bhunia, D., 2019. Analytical and experimental investigations on using waste marble powder in concrete. Journal of Materials in Civil Engineering 31, 04019011.

[13] Singh, M., Srivastava, A., Bhunia, D., 2019. Long term strength and durability parameters of hardened concrete on partially replacing cement by dried waste marble powder slurry. Construction and Building Materials 198, 553-569.

[14] Ulubeyli, G.C., Bilir, T., Artir, R., 2016. Durability properties of concrete produced by marble waste as aggregate or mineral additives. Procedia engineering 161, 543-548.

[15] Vardhan, K., Siddique, R., Goyal, S., 2019. Strength, permeation and micro-structural characteristics of concrete incorporating waste marble. Construction and Building Materials 203, 4555.

[16] Ashish, D.K., 2018. Feasibility of waste marble powder in concrete as partial substitution of cement and sand amalgam for sustainable growth. Journal of Building Engineering 15, 236-242.

[17] Ashish, D.K., 2019. Concrete made with waste marble powder and supplementary cementitious material for sustainable development. Journal of cleaner production 211, 716-729.

[18] Gameiro, F., De Brito, J., da Silva, D.C., 2014. Durability performance of structural concrete containing fine aggregates from waste generated by marble quarrying industry. Engineering Structures 59, 654-662.

[19] Singh, M., Choudhary, K., Srivastava, A., Sangwan, K.S., Bhunia, D., 2017. A study on environmental and economic impacts of using waste marble powder in concrete. Journal of Building Engineering 13, 87-95.

[20] Kumar, A., Thakur, A., 2018. A State of Art Review: On Usage of Waste Marble Powder In Concrete Production. 
Study of the durability against carbonation of the concrete formulated with the partial replacement of cement with marble powder

[21] Rana, A., Kalla, P., Csetenyi, L.J., 2015. Sustainable use of marble slurry in concrete. Journal of Cleaner Production 94, 304-311.

[22] P. ROUGEAU, " AFREM crossover test results, Accelerated carbonation test," CERIB, 1997.

[23]Bouziani, T., Benmounah, A., 2013. Correlation between v-funnel and mini-slump test results with viscosity. KSCE Journal of Civil Engineering 17, 173-178.

[24] Tayeh, B.A., 2018. Effects of marble, timber, and glass powder as partial replacements for cement. Journal of Civil Engineering and Construction 7, 63-71. 